\title{
ANALISANDO DOCUMENTOS DE QUATRO CAPITAIS DA REGIÃO NORDESTE PARA O ENSINO DE MÚSICA NAS SÉRIES INICIAIS DO ENSINO FUNDAMENTAL
}

\author{
Sérgio Luiz Ferreira de Figueiredo; Fernanda Rosa da Silva \\ Departamento de Música - CEART - UDESC \\ Projeto de Pesquisa: Os efeitos da legislação educacional para a educação musical nas séries \\ iniciais: 10 anos de LDBEN e outros documentos. \\ Grupo de Pesquisa MUSE - Música e Educação \\ sergiofigueiredo@udesc.br; fernanda_rosa9@yahoo.com.br
}

\section{RESUMO}

A partir da Lei 9394 de 1996 (Lei de Diretrizes e Bases da Educação Nacional LDBEN), o ensino de arte foi estabelecido como sendo obrigatório em todos os níveis da educação básica. Apesar desta obrigatoriedade, tanto a LDB quanto outros documentos nacionais que foram elaborados posteriormente não estabeleceram claramente as linguagens artísticas a serem ministradas na escola, nem o tipo de profissional que deveria ser responsável pelo ensino de cada uma destas linguagens. Estados e municípios decidem sobre o ensino de arte que desejam oferecer e a música nem sempre tem estado presente nas escolas. O objetivo deste trabalho é analisar documentos oficiais sobre o ensino de música nas séries iniciais do ensino fundamental em quatro capitais da região nordeste do Brasil. A pesquisa qualitativa tem sido referência para o desenvolvimento desta pesquisa, utilizando-se principalmente a análise documental como instrumento de coleta de dados. A análise dos documentos revela a precariedade da orientação referente ao ensino de música para as séries iniciais. Tais documentos precisam de revisão para que possam contribuir para o desenvolvimento musical das crianças nesta faixa etária.

PALAVRAS-CHAVE: educação musical, legislação educacional, séries iniciais

\section{INTRODUÇÃO}

No presente trabalho são utilizados dados parciais do projeto de pesquisa intitulado “Os efeitos da legislação educacional para a educação musical nas séries iniciais: 10 anos de LDBEN e outros documentos". Esta pesquisa, iniciada em 2006, abrange o estudo da legislação produzida por estados e capitais brasileiras a partir de 1996 da aprovação da Lei 9.394/96 - Lei de Diretrizes e Bases da Educação Nacional - LDBEN (BRASIL, 1996). No ano de 2007 foram estudados documentos dos estados e em 2008 os documentos das capitais. O objetivo desta etapa da investigação é refletir sobre a situação do ensino de música nas quatro primeiras séries do ensino fundamental a partir do estudo da legislação vigente nas capitais brasileiras. Ao discutir os dados levando em consideração a literatura da área, pretende-se apresentar propostas de aperfeiçoamento para os documentos encontrados.

1 - Os efeitos da legislação educacional para a educação musical nas séries iniciais: 10 anos de LDBEN e outros documentos $=$ CEART

2 - Prof. Sérgio Luiz Ferreira de Figueiredo = Departamento de Música

3 - Fernanda Rosa da Silva - PIBIC - Licenciatura em Educação Artística - Habilitação: Música 


\section{METODOLOGIA}

A pesquisa qualitativa com ênfase na análise documental foi escolhida como modelo para esta investigação. Foram desenvolvidas atividades que contemplaram desde a coleta de dados, sua tabulação e análise do material encontrado, além da leitura de textos que discutem o assunto e confecção de trabalhos para divulgação deste estudo. Desta forma foram reunidos e analisados documentos de âmbito nacional (LDB e PCN) e sua derivação municipal, com publicação posterior a 1996.

A coleta de documentos municipais passou por duas etapas. A primeira etapa foi desenvolvida através de pesquisa via internet, com visitas periódicas aos websites oficiais das secretarias de educação, visando encontrar documentos que tratassem do tema da pesquisa música nas séries iniciais. A segunda etapa da coleta de dados consistiu do envio de correspondência escrita para as secretarias de educação das capitais brasileiras, expondo os objetivos da pesquisa e solicitando informações sobre como é oferecido o ensino da música nas SIEF (séries iniciais no ensino fundamental). Todos os documentos encontrados e as cartas recebidas foram organizados, tabulados e analisados de modo a evidenciar os aspectos relevantes para esta pesquisa.

A região Nordeste, neste trabalho, é colocada em destaque, representada por quatro capitais: Teresina (PI), Recife (PE), São Luiz (MA) e João Pessoa (PB). Após uma revisão da literatura será apresentada a análise dos documentos de cada capital sendo, posteriormente, as orientações encontradas para a o ensino de música nas SIEF colocadas em discussão.

\section{REVISÃO DA LITERATURA}

A atual versão da LDBEN 9.394/96 (Lei de Diretrizes e Bases da Educação Nacional) institui princípios básicos para o ensino brasileiro com vistas à formação do cidadão, apresentando subsídios à formação de planos e políticas educacionais, a serem desenvolvidos por Estados e Municípios. A LDBEN em seu título IV - da organização da educação nacional - estabelece que Estados e Municípios devem "elaborar e executar políticas e planos educacionais [complementares], em consonância com as diretrizes e planos nacionais de educação” (BRASIL, 1996, art. 10 e 11). Para tal, a lei prevê no artigo 26 que os

currículos do ensino fundamental ... devem ter uma base nacional comum, a ser complementada, em cada sistema de ensino e estabelecimento escolar, por uma parte diversificada, exigida pelas características regionais e locais da sociedade, da cultura, da economia e da clientela. (Brasil, 1996, art. 26)

1 - Os efeitos da legislação educacional para a educação musical nas séries iniciais: 10 anos de LDBEN e outros documentos = CEART

2 - Prof. Sérgio Luiz Ferreira de Figueiredo = Departamento de Música

3 - Fernanda Rosa da Silva - PIBIC - Licenciatura em Educação Artística - Habilitação: Música 
Desta forma, compete aos dirigentes estaduais e municipais o compromisso de inserir em sua proposta curricular valores próprios de sua localidade de modo a acolher as particularidades existentes em sua rede de ensino. Isto significa considerar as possibilidades e limitações inerentes a cada sistema, ao ser avaliada, por exemplo, a configuração dos profissionais atuantes, as condições das instituições de ensino e as necessidades educacionais das comunidades atendidas, antes de concluir um parâmetro curricular.

No capítulo II do artigo 26 a LDB determina que "o ensino da arte constituirá componente curricular obrigatório, nos diversos níveis da educação básica, de forma a promover o desenvolvimento cultural dos alunos" (BRASIL, 1996, art. 26). No entanto, não há maiores detalhes acerca de que arte deverá ser ensinada, que modalidades ou linguagens serão apresentadas, ou que tipo de formação profissional seria exigida dos profissionais responsáveis por estas áreas de atuação no currículo escolar.

A fim de complementar as orientações definidas pela LDBEN para o Ensino Fundamental foram publicados pelo MEC, em 1997, os Parâmetros Curriculares Nacionais PCN. Estes vêem orientar os sistemas de ensino na geração do currículo escolar e na prática dos profissionais da educação. Será analisado para este estudo o primeiro conjunto de documentos que orientam o ensino de arte para as séries iniciais do Ensino Fundamental. No volume Arte o documento apresenta uma caracterização da área e seu ensino, expondo seus fins, critérios de avaliação e conteúdos para o Ensino Fundamental. Ao definir a área, o documento destaca que esta possui "uma função tão importante quanto a dos outros conhecimentos no processo de ensino e aprendizagem. A área de Arte está relacionada com as demais áreas e tem suas especificidades” (BRASIL, 1997, p. 19). Também define que o ensino de arte é composto por quatro modalidades artísticas: artes visuais, teatro, dança e música.

Ao descrever cada linguagem artística os PCN adotam "não explicitamente, os eixos da chamada 'Metodologia Triangular' - ou melhor, 'Proposta Triangular'” (Penna, 2001, p. 39) na organização dos conteúdos: produção, fruição e reflexão devem estar integrados na prática educativa. Esta proposta triangular, defendida por Ana Mae Barbosa, tem sido amplamente utilizada pela área de artes visuais.

O desenvolvimento de um ensino que garanta a prática musical com conteúdos específicos da linguagem dependerá também da capacitação do professor que a leciona. Os

1 - Os efeitos da legislação educacional para a educação musical nas séries iniciais: 10 anos de LDBEN e outros documentos = CEART

2 - Prof. Sérgio Luiz Ferreira de Figueiredo = Departamento de Música

3 - Fernanda Rosa da Silva - PIBIC - Licenciatura em Educação Artística - Habilitação: Música 
documentos nacionais determinam a obrigatoriedade do ensino de arte, porém não esclarecem quem deverá ser este profissional, e na prática, esta disciplina nas séries inicias fica geralmente sob a responsabilidade do professor de classe, ou generalista (BELLOCHIO, 2000).

O profissional generalista na maioria dos casos não possui uma formação suficiente em música para lecioná-la de maneira consistente para cumprir os conteúdos musicais especificados nos PCN. Em um estudo realizado por Figueiredo (2004) constatou-se que na maior parte dos cursos de Pedagogia a música é abordada de forma superficial em seus currículos, sendo que em diversos cursos a música sequer está presente. A situação agrava-se pela significante ausência de professores especialistas contratados para atuarem em música nas SIEF.

O resultado dessa falta de professores especialistas ... associado ao despreparo dos professores generalistas para compreenderem e incluírem música em sua prática escolar, tem contribuído para uma ausência significativa da educação musical nos primeiros anos escolares. (FIGUEIREDO, 2004, p. 56)

Assim, consta nos documentos nacionais que o ensino de arte/música é entendido como um elemento curricular importante na formação do cidadão brasileiro e, portanto, deve apresentar-se como disciplina na proposta educacional de estados e municípios. No entanto, não há clareza suficiente sobre diversos aspectos que são fundamentais para o desenvolvimento de uma educação musical consistente nas séries iniciais do ensino fundamental.

Esta compreensão de como é estruturado o ensino brasileiro associado às considerações feitas pelos autores aqui citados nos levam a entender como se apresenta o material considerado referência para o sistema educacional brasileiro. Os PCN, mesmo não sendo obrigatórios, significam referenciais para muitos sistemas educacionais, mesmo sendo incompletos e ambíguos em diversos sentidos. As reflexões sobre a legislação vigente ajudam a compreender como são utilizados e interpretados este documentos pelas capitais estudadas na organização de seus parâmetros de ensino.

\section{APRESENTAÇÃO E DISCUSSÃO DOS DADOS}

Foram estudadas para este trabalho quatro cidades da região Nordeste: Teresina/PI , Recife/PE, João Pessoa/PB e São Luiz/MA. O material aqui apresentado foi coletado através

1 - Os efeitos da legislação educacional para a educação musical nas séries iniciais: 10 anos de LDBEN e outros documentos = CEART

2 - Prof. Sérgio Luiz Ferreira de Figueiredo = Departamento de Música

3 - Fernanda Rosa da Silva - PIBIC - Licenciatura em Educação Artística - Habilitação: Música 
da internet nas páginas oficiais das capitais, assim como através de respostas enviadas pelas secretarias municipais de educação. Serão apresentados os documentos analisados de cada município e destacadas as informações que demonstram como é oferecido o ensino de música nas SIEF das referidas cidades.

\section{Teresina - PI}

Compõem os documentos estudados deste município as Diretrizes Curriculares do Município de Teresina (fevereiro de 2008) e o conteúdo da carta com as respostas enviadas pela Secretaria Municipal de Educação. Através da análise das diretrizes curriculares observase que, dentro de uma mesma série, são apresentados conteúdos e habilidades que contemplam a música, o teatro, as artes visuais e a dança. Os conteúdos, que abrangem elementos específicos da linguagem musical, estão articulos em três eixos: Eixo I: Produção Artística, Eixo II: Apreciação estética, Eixo III: História da Arte. Nota-se aqui a presença da Proposta Triangular na organização dos conteúdos.

Na carta consta a informação de como o ensino da música deve ser articulado na prática escolar, conforme as seguintes orientações das diretrizes. "O projeto Político Pedagógico... da nossa Rede Pública Municipal contempla um conjunto de proposições e procedimentos conceituais e metodologias que permitem a integração do fazer artístico musical..." (TERESINA, 2008, p.1).

\section{Recife - PE}

Norteia o ensino de arte na Proposta Pedagógica de Recife (2001-2004) a Proposta Triangular e, conforme o documento, a música "interage bem com as demais linguagens: literária; cênica e visual, como também com as outras áreas do conhecimento. Seu caráter interdisciplinar é abrangente" (RECIFE, 2001-2004, p.21). Este documento expõe uma tabela com conteúdos específicos em música para cada ciclo do ensino Fundamental.

\section{São Luiz - MA}

A fonte de dados desta capital estudada está nas informações da carta resposta (enviada em dezembro de 2007) que contem em anexo a Proposta Curricular de São Luiz. A disciplina Arte (música, dança, artes visuais e teatro) para os $1^{\circ}$ e $2^{\circ}$ ciclos $\left(1^{\mathrm{a}}\right.$ a $5^{\mathrm{a}}$ séries) é desenvolvida a partir

1 - Os efeitos da legislação educacional para a educação musical nas séries iniciais: 10 anos de LDBEN e outros documentos $=$ CEART

2 - Prof. Sérgio Luiz Ferreira de Figueiredo = Departamento de Música

3 - Fernanda Rosa da Silva - PIBIC - Licenciatura em Educação Artística - Habilitação: Música 
da Proposta Triangular sendo cada modalidade artística descrita em conteúdos e capacidades para cada um dos três eixos. Para a música são expostos conteúdos que valorizam a cultura regional e também apresentam elementos bastante específicos na área.

A carta enviada pela Secretaria de Educação do município de São Luiz apresenta uma informação sobre a música, indicando que naquela rede de ensino não há "ensino da música como disciplina curricular" (SÃO LUIZ, 2007, p. 1). Diante desta informação compreende-se a ausência de aula de música especificamente, mas de acordo com a Proposta Curricular de São Luiz a música faz parte dos conteúdos relativos ao ensino de arte.

\section{João Pessoa-PB}

O ensino de Música nas SIEF está contemplado na Proposta Curricular do município de João Pessoa. Em correspondência enviada pela Diretoria de Gestão Curricular, afirma-se que o ensino de música está ainda em processo de implantação. Na Proposta Curricular de João Pessoa (2004) a música deverá ser desenvolvida nas $2^{\mathrm{a}}, 3^{\mathrm{a}}$ e $4^{\mathrm{a}}$ séries. Neste documento estão indicados os objetivos da música no currículo daquela rede escolar, que devem ser desenvolvidos pelo professor. Alguns exemplos destes objetivos são: entender a arte enquanto campo de conhecimento e estabelecer inter-relações entre arte e outras disciplinas, identificar e caracterizar elementos da música; identificar estilos e gêneros musicais, apreciar e valorizar a música regional e identificar e aplicar elementos da linguagem musical (JOÃO PESSOA, 2004).

\section{ANÁLISE DOS DADOS}

Podemos constatar nesta apresentação dos documentos municipais que a música está presente nos parâmetros examinados, e com esta pesquisa surgem nos documentos avaliados alguns pontos importantes para discussão com relação às suas orientações para o ensino musical nas séries iniciais. Em quase todas as capitais é utilizada como fundamentação e metodologia para o ensino de música a Proposta Triangular, organizando os conteúdos para as SIEF. Este dado converge com os resultados de um estudo realizado por Fernandes (2004) que também analisou as propostas para o ensino musical em documentos estaduais e municipais.

Fonterrada (2005) e Penna (2001) discutem sobre as implicações que esta disposição

1 - Os efeitos da legislação educacional para a educação musical nas séries iniciais: 10 anos de LDBEN e outros documentos $=$ CEART

2 - Prof. Sérgio Luiz Ferreira de Figueiredo = Departamento de Música

3 - Fernanda Rosa da Silva - PIBIC - Licenciatura em Educação Artística - Habilitação: Música 
dos conteúdos musicais (pela Proposta Triangular) pode gerar na prática docente. Entre os três eixos somente a "produção" se refere ao fazer musical. Penna (2001) assim reflete sobre esta desproporção de conteúdos práticos e teóricos apresentados pelos PCN-Arte para o ensino de música. Não negamos em absoluto a validade - e mesmo a necessidade - de um
trabalho que envolva discussão e reflexão. ... No entanto, a profusão de
conteúdos voltados para a discussão e habilidades correlatas pode vir a
favorecer uma prática pedagógica centrada no falar sobre música, sem a
presença concreta do sonoro-musical em sala de aula. (PENNA, 2001, p.
129)

Do mesmo modo, Fernandes (2004) comenta que, "as três diretrizes da proposta triangular são propícias para todas as áreas da arte, embora seu uso [na prática] seja, ainda, quase que especificamente nas artes plásticas” (FERNANDES, 2004, p.77). O autor ainda alerta quanto à aplicação desta proposta em Arte/Música, pois se "os professores que a adotam forem mal preparados, a "releitura" pode virar uma simples cópia, não contribuindo para a consciência da linguagem artística" (idem, p.77).

Em quase todas as cidades pesquisadas não é informada a qualificação profissional necessária para o ensino de música, sugerindo que são os professores pedagogos responsáveis por todas as áreas do currículo das séries iniciais, o que inclui a música e as artes. Em Teresina, por exemplo, no Edital de concurso público de 2006 para o cargo de professor dos anos iniciais, não é avaliado na prova o conhecimento de arte/música do candidato; só é exigida a formação em curso de nível médio Normal ou superior de pedagogia. Entende-se assim que a Secretaria Municipal acredita que estes títulos habilitam o profissional a cumprir com os conteúdos em musica exigidos em sua Diretriz Curricular.

Entretanto, como tem sido amplamente discutido na literatura da área, os cursos de pedagogia raramente contemplam as artes com conteúdos específicos de cada linguagem. Assim, fica difícil entender com esta indefinição profissional como o ensino musical apresenta-se nestas capitais. No documento de São Luiz é assegurado que sua "proposta de conteúdos é perfeitamente adaptável ao planejamento do(a) professor(a) com base em sua realidade escolar" (SÃO LUIZ, 2007, p.1). Será que os professores pedagogos, neste caso, participam de cursos de capacitação para lecionar os conteúdos propostos oferecidos pela prefeitura, ou fica a seu critério decidir quais as linguagens artísticas que farão parte das atividades curriculares de acordo com sua formação ou preferência?

1 - Os efeitos da legislação educacional para a educação musical nas séries iniciais: 10 anos de LDBEN e outros documentos = CEART

2 - Prof. Sérgio Luiz Ferreira de Figueiredo = Departamento de Música

3 - Fernanda Rosa da Silva - PIBIC - Licenciatura em Educação Artística - Habilitação: Música 
Somente o município de João Pessoa demonstrou em suas informações ciência desta questão profissional, buscando alternativas que possam garantir nas SIEF a efetiva inclusão do ensino musical. Este município oferece cursos em Arte com especialização em cada modalidade artística para professores da rede municipal e promove concursos para o cargo de professor especialista em música com atuação nas séries iniciais. Apesar deste aspecto positivo daquela rede municipal, a diretora de gestão curricular relata na correspondência enviada que ainda são encontradas dificuldades para resolver a situação do ensino musical. Tal fato pode estar relacionado à recente implantação (2004) e adaptação pelas escolas da nova concepção dada ao ensino de música. A diretora relata que

durante todo o ano [permaneceu] a dificuldade de conseguir professores Licenciados em Música disponíveis para o exercício.........Em 2008, com a realização do concurso e um considerável número de vagas para o professorado de Música esperamos avançar e sanar a desvantagem existente em relação a este ensino [musical] nas séries iniciais. (JOÃO PESSOA, 2007, p. 1)

Nos quatro contextos municipais são apresentados conteúdos bastante específicos da linguagem musical, mas questiona-se se tais conteúdos na prática docente são realmente oferecidos. As expressões a seguir permitem uma leitura polivalente do ensino musical: a música 'interage bem com as demais linguagens Seu caráter interdisciplinar é abrangente" (Recife, 12001-2004, p.21), “O Projeto Político Pedagógico ... contempla um conjunto e proposições e procedimentos conceituais e metodologias que permitem a integração do fazer artístico musical." (TERESINA, 2008, p. 1).

Em São Luiz e João Pessoa nota-se a preocupação em abarcar conteúdos que valorizem a cultura e a música regional, o que significa que seus documentos aproveitam a flexibilidade oferecida pelas orientações nacionais. Como relata Fernandes (2004), “ a 'base' nacional não abrange a diversidade da cultura brasileira, mas indica que cada localidade se responsabilize por isto" (FERNANDES, 2004, p. 78). Esta possibilidade de adaptação, resguardada pela lei, permite a formação de projetos regionais mais democráticos que atendam a realidade educacional local.

Sendo assim, na maior parte dos documentos municipais estudados, não há uma garantia de que nas escolas da rede é oferecido o ensino musical. Seguindo a mesma falta de orientação na LDBEN e nos PCN sobre o tipo de profissional que deveria ser responsável pelo ensino de cada linguagem artística, os documentos municipais analisados também não apresen1 - Os efeitos da legislação educacional para a educação musical nas séries iniciais: 10 anos de LDBEN e outros documentos = CEART

2 - Prof. Sérgio Luiz Ferreira de Figueiredo = Departamento de Música

3 - Fernanda Rosa da Silva - PIBIC - Licenciatura em Educação Artística - Habilitação: Música 
tam tal tipo de informação.

\section{CONSIDERAÇÕES FINAIS}

Apesar de constar na LDBEN que o "ensino de arte" é obrigatório na educação básica, e portanto nas SIEF, isto não significa a certeza de que a música esteja presente nos currículos escolares. Nos PCN ela é considerada imprescindível para a formação do cidadão crítico, consciente de sua cultura e, através da apropriação doa elementos específicos, capaz de expressar-se musicalmente.

Para que a aprendizagem da música possa ser fundamental na formação de cidadãos é necessário que todos tenham a oportunidade de participar ativamente como ouvintes, intérpretes, compositores e improvisadores, dentro e fora da sala de aula. (BRASIL, 1997, p. 54)

Por ser a música compreendida como uma ramificação da Arte nos documentos oficiais, de acordo com Fonterrada (2004, 2005), Figueiredo (2005) e Penna (2004), esta área acaba por apresentar, na prática, um caráter polivalente. Este ensino polivalente, que se caracteriza pela dissolução dos conteúdos específicos, ganha espaço na medida em que os documentos nacionais deixam a critério das escolas e secretarias de educação definir em seus planejamentos como a arte deverá ser desenvolvida (PCN, 1997b). Assim, concordamos com Penna (2004) ao ressaltar que

por um lado, a atual LDB refere-se à arte de forma imprecisa, ao mesmo tempo em que os Parâmetros ... estabelecem um espaço potencial para a música como parte do conteúdo escolar "Arte", sem contudo garantir a sua efetiva presença na prática escolar, que depende, fundamentalmente, das decisões pedagógicas de cada escola. Assim ... a música, como conteúdo curricular, continua subordinada ao campo mais amplo e múltiplo das artes. (PENNA, 2004, p. 25)

Figueiredo (2005) também discute sobre os efeitos desta falta de delimitação dos contornos curriculares para o ensino de arte/música nas SIEF.

Os PCN, as diretrizes de estados e municípios e outros documentos emitidos pelas autoridades educacionais não apresentam uma clareza em termos de políticas educacionais para o ensino das artes. O que tem ocorrido é uma continuação da prática anterior - polivalência - agora com a anuência da própria lei. (FIGUEIREDO, 2005, p. 24)

1 - Os efeitos da legislação educacional para a educação musical nas séries iniciais: 10 anos de LDBEN e outros documentos $=$ CEART

2 - Prof. Sérgio Luiz Ferreira de Figueiredo = Departamento de Música

3 - Fernanda Rosa da Silva - PIBIC - Licenciatura em Educação Artística - Habilitação: Música 
Mas da mesma forma que há esta ambigüidade nos documentos tanto a LDBEN como os PCN afirmam que suas determinações não possuem a intenção de homogeneizar o ensino, permitindo sua adaptação aos diversos contextos locais. Fonterrada (2005) reflete sobre a distância entre a teórica e a aplicação desta flexibilidade.

Ao trazer estados e municípios à coparticipação no processo educativo da população ... mostram-se vantagens de ações conjuntas para a recuperação do sistema educativo do país. No entanto, a par do discurso otimista, deve se ter em mente a enormidade da tarefa e a distância entre a proposta e sua aplicação prática, pois anos e anos de ações inadequadas ... deixaram a educação em um estado em que somente um plano muito bem urdido, a colaboração de muitos profissionais, a montagem de cursos e atividades de formação continuada... poderão mudar a situação hoje vivida.” (FONTERRADA, 2005, 246-247)

Da mesma forma que a flexibilidade possibilita a inserção nos documentos das capitais de elementos culturais próprios da região, pode possibilitar a geração de políticas educacionais que incluam o ensino da música de maneira significativa para a formação escolar. Assim, como discorre Penna (2004), as orientações previstas nos documentos nacionais

podem se articular a determinações em nível estadual ou municipal, onde poderia ser estabelecida, por exemplo, a obrigatoriedade do ensino de música - em sua especificidade e com espaço curricular próprio - na rede de ensino correspondente. (PENNA, 2004, p. 26-27)

O modo como os documentos nacionais (LDBEN e PCN) apresentam o ensino musical possibilita diferentes interpretações. Nestes documentos oficiais faltam orientações precisas sobre como os conteúdos específicos de músicas deverão ser oferecidos e sobre o profissional encarregado em lecionar a área, por exemplo, o que também pode ser observado nos documentos municipais analisados. Mesmo que os PCN não sejam documentos considerados obrigatórios é importante lembrar que estes muitas vezes norteiam a formulação de parâmetros de ensino estadual e municipal, e por este motivo é fundamental que sejam revistos tais documentos para que se ofereça uma educação com qualidade, incluindo música no currículo.

Nos documentos analisados nota-se que o município de João Pessoa está procurando meios de retomar o ensino musical em suas escolas, com a abertura de concursos públicos para profissionais especialistas na área e ainda oferece cursos de formação continuada em música para professores generalistas. Esta iniciativa certamente promoverá a presença da música para muitos estudantes daquela rede municipal, propiciando uma formação educacional mais ampla.

1 - Os efeitos da legislação educacional para a educação musical nas séries iniciais: 10 anos de LDBEN e outros documentos = CEART

2 - Prof. Sérgio Luiz Ferreira de Figueiredo = Departamento de Música

3 - Fernanda Rosa da Silva - PIBIC - Licenciatura em Educação Artística - Habilitação: Música

DAPesquisa, Florianópolis, v.3 n.5, p.671-683, 2008. 
Quando há por parte das autoridades regionais a preocupação de construir parâmetros curriculares claros que considerem as necessidades e particularidades do ensino local, como também oferecer uma educação para a cidadania, permitindo o acesso a linguagem musical, o ensino se enriquece como um todo, construindo um panorama da educação que valorize a pluralidade cultural do nosso país. Por esta razão, a revisão de documentos oficiais com relação à música nos anos iniciais do ensino fundamental é necessária para que se aprimorem os currículos escolares e, conseqüentemente, a formação escolar oferecida para todos os brasileiros.

\section{REFERÊNCIAS BIBLIOGRÁFICAS}

BELLOCHIO, Cláudia Ribeiro. A Educação Musical na escola: alguns enfoques. In: A educação musical nas séries iniciais do ensino fundamental: olhando e construindo junto às práticas cotidianas do professor. Tese de doutorado. Universidade Federal do Rio Grande do Sul, Faculdade de Educação, Programa de Pós-Graduação em Educação. Porto Alegre, RS: UFRGS, 2000, p. 97-104.

BELLOCHIO, Cláudia Ribeiro. O Professor das séries iniciais e o ensino de Música na escola: entrelaçamentos entre a formação e ação desse profissional. In: A educação musical nas séries iniciais do ensino fundamental: olhando e construindo junto às práticas cotidianas do professor. Tese de doutorado. Universidade Federal do Rio Grande do Sul, Faculdade de Educação, Programa de Pós-Graduação em Educação. Porto Alegre, RS: UFRGS, 2000, p. 118-127.

BRASIL, Congresso Nacional. Lei de Diretrizes e Bases da Educação Nacional (9394/96) Diário Oficial da União. Brasília, 24 de dezembro de 1996.

BRASIL. Ministério da Educação e do Desporto. Secretaria de Educação Fundamental. Parâmetros Curriculares Nacionais: Introdução. Disponível em: $\lfloor$ http://www.mec.gov.br/sef/estrut2/pcn/pcn1a4.asp〉. Brasília, v.1, 1997a.

BRASIL. Ministério da Educação e do Desporto. Secretaria de Educação Fundamental. Parâmetros Curriculares $\quad$ Nacionais. $\quad$ Arte. Disponível em:<http://www.mec.gov.br/sef/estrut2/pcn/pcn1a4.asp >. Brasília, v.6, 1997b.

FERNANDES, José Nunes. Normalização, estrutura e organização do ensino da música nas escolas de educação básica do Brasil: LDBEN/96, PCN e currículos oficiais em questão. Revista da Associação Brasileira de Educação Musical - ABEM, Porto Alegre, RS, n. 10, p. 75-67, março de 2004.

FIGUEIREDO Sérgio Luiz Ferreira de. A preparação Musical de Professores generalistas no Brasil. Revista da Associação Brasileira de Educação Musical - ABEM, Porto Alegre, RS, n. 1 - Os efeitos da legislação educacional para a educação musical nas séries iniciais: 10 anos de LDBEN e outros documentos $=$ CEART

2 - Prof. Sérgio Luiz Ferreira de Figueiredo = Departamento de Música

3 - Fernanda Rosa da Silva - PIBIC - Licenciatura em Educação Artística - Habilitação: Música 
11, p. 55-60, setembro de 2004.

FIGUEIREDO, Sérgio Luiz Ferreira de. Educação musical nos anos iniciais da escola: identidade e políticas educacionais. Revista da Associação Brasileira de Educação Musical ABEM, Porto Alegre, RS, n. 12, p.21-29, março de 2005.

FONTERRADA, Marisa Trench de Oliveira. Desenredando a trama da música na escola brasileira. In: De tramas e fios: um ensaio sobre música e educação. São Paulo: UNESP, 2005, p. 244-259.

FONTERRADA. Marisa Trench de Oliveira. Reflexões a respeito do ensino de música em escolas que não são de música. In: II Encontro de Pesquisa em Música da Universidade Estadual de Maringá. Maringá: Massoni, 2004, p. 34-40.

JOÃO PESSOA. Carta enviada ao pesquisador. João Pessoa: Diretoria de Gestão Curricular, janeiro de 2008.

JOÃO PESSOA. Proposta Curricular da Rede Municipal de Ensino de João Pessoa. João Pessoa: Diretoria de Gestão Curricular, 2004.

PENNA, Maura. A dupla dimensão da política educacional e a música na escola: 1- analisando a legislação e termos normativos. Revista da Associação Brasileira de Educação Musical - ABEM, Porto Alegre, RS, n. 10, p. 19-28, março de 2004.

PENNA, Maura (coord.). É este o ensino de arte que queremos? Uma análise das propostas dos parâmetros curriculares nacionais. João Pessoa: Editora Universitária/CCHLA/PPGE, 2001.

RECIFE. Proposta Pedagógica da Rede Municipal de Ensino do Recife - Construindo Competência. Recife: Secretaria Municipal de Educação, 2001-2004.

SÃO LUIZ. Carta enviada ao pesquisador. São Luiz: Secretaria Municipal de Educação, dezembro de 2007.

SÂO LUIZ. Proposta Curricular Arte para os $1^{o}$ e $2^{o}$ ciclos $\left(1^{a}\right.$ a $5^{a}$ séries). São Luiz: Secretaria Municipal de Educação, s/d.

SOUZA, Jusamara. Parâmetros Curriculares Nacionais: Ensino Fundamental e Médio, Política e Ações para o Ensino de Música nas Escolas. In: ENCONTRO ANUAL DA ASSOCIAÇÃO BRASILEIRA DE EDUCAÇÃO MUSICAL - ABEM, 7, 1998, Recife, Anais... Recife: ABEM, 1998, p. 17 - 26.

TERESINA. Edital n. ${ }^{\circ}$ 1/2006 (de concurso público para os cargos de Professor e de 1 - Os efeitos da legislação educacional para a educação musical nas séries iniciais: 10 anos de LDBEN e outros documentos = CEART

2 - Prof. Sérgio Luiz Ferreira de Figueiredo = Departamento de Música

3 - Fernanda Rosa da Silva - PIBIC - Licenciatura em Educação Artística - Habilitação: Música 
Pedagogo da Secretaria Municipal de Educação e Cultura). Teresina: Secretaria Municipal de Educação e Cultura, outubro de 2006.

TERESINA. Diretrizes Curriculares do Município de Teresina. Teresina: Secretaria Municipal de Educação e Cultura, fevereiro de 2008.

TERESINA. Carta enviada ao pesquisador. Secretaria Municipal de Educação e Cultura, abril de 2008.

1 - Os efeitos da legislação educacional para a educação musical nas séries iniciais: 10 anos de LDBEN e outros documentos = CEART

2 - Prof. Sérgio Luiz Ferreira de Figueiredo = Departamento de Música

3 - Fernanda Rosa da Silva - PIBIC - Licenciatura em Educação Artística - Habilitação: Música

DAPesquisa, Florianópolis, v.3 n.5, p.671-683, 2008. 